\title{
Are You Thinking What I'm Thinking? The Case for Shared Mental Models in Hospital Discharges
}

\author{
Amanda P Bettencourt, PhD, APRN, CCRN-K, ACCNS-P1*, Amanda C Schondelmeyer, MD, MSc ${ }^{2}$
}

${ }^{1}$ University of Michigan School of Nursing, Department of Systems, Populations, and Leadership, Ann Arbor, Michigan; ${ }^{2}$ Department of Pediatrics, University of Cincinnati College of Medicine, Cincinnati, Ohio, Division of Hospital Medicine, Cincinnati Children's Hospital Medical Center, Cincinnati, Ohio.

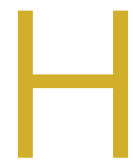

ospital discharge is a complex, multi-stakeholder event, and evidence suggests that the quality of that transition directly relates to mortality, readmissions, and postdischarge quality of life and functional status. ${ }^{1}$ The Centers for Medicare \& Medicaid Services call for team-based and patient-centered discharge planning, ${ }^{2}$ yet the process for achieving this is poorly defined.

In this issue of the Journal of Hospital Medicine, Manges et al $^{3}$ use shared mental models (SMM) as a conceptual framework to describe differences in how care team members and patients perceive hospital discharge readiness. While our understanding of factors associated with safe and patient-centered hospital discharges is still growing, the authors focus on one critical component: lack of agreement between patients and interprofessional teams regarding discharge readiness.

Manges et $\mathrm{al}^{3}$ measured whether interprofessional team members agree, or converge, on their assessment of a patient's discharge readiness (team-SMM convergence) and whether that assessment converges with the patient's self-assessment (team-patient SMM convergence). They found good teamSMM convergence regarding the patient's discharge readiness, yet teams overestimated readiness compared with the patient's self-assessment nearly half (48.4\%) of the time. A clinical trial found that clinician assessments of discharge readiness were poorly predictive of readmissions unless they were combined with a patient's self-assessment. ${ }^{4}$ Manges et al's study findings, while of limited generalizability, enhance our understanding of a potential gap in achieving patient-centered care as outlined in the Institute of Medicine's Crossing the Quality Chasm, ${ }^{5}$ which urges clinicians to see patients and families as partners in improving care.

The authors also found that higher team-patient convergence was associated with teams that reported high-quality teamwork and those having more baccalaureate degreeeducated nurses (BSN). While Manges et al ${ }^{3}$ did not elucidate the mechanism by which this occurs, their findings align with existing literature showing that patients receiving care from a higher proportion of BSN-prepared nurses experience an $18.7 \%$ reduction in odds of readmission. ${ }^{6}$ Further research

*Corresponding Author: Amanda P Bettencourt, PhD, APRN, CCRN-K, ACCNS-P; Email: abetten@med.umich.edu.

Received: January 29, 2021; Accepted: January 30, 2021

๑) 2021 Society of Hospital Medicine DOI 10.12788/jhm.3606 investigating the link between team communication, registered nurse education, and discharge outcomes may reveal additional opportunities for interventions to improve discharge quality.

The lack of patient outcomes and the limited diversity of the patient population are substantial limitations of the study. The authors did not assess the relationship between SMMs and important outcomes like readmission or adverse events. Furthermore, most of the patients were White and Englishspeaking, precluding assessment of factors that disproportionately impact patient populations that already experience disparities in a multitude of health outcomes.

In summary, Manges et al ${ }^{3}$ highlight challenges and opportunities in optimizing clinician communication and ensuring that the team's and the patient's self-assessments align and inform discharge planning. Their findings suggest the theoretical framework of SMM holds promise in identifying and evaluating some of the complex determinants involved in highquality, patient-centered hospital discharges.

Disclosures: The authors have no conflicts to disclose.

Funding: Dr Bettencourt's work is supported, in part, by the National Institutes of Health, National Heart, Lung, and Blood Institute (5K12HL13803903). Dr Schondelmeyer receives support from the Agency for Healthcare Research and Quality (K08HS026763) and from the Association for the Advancement of Medical Instrumentation Foundation.

\section{References}

1. Naylor MD, Brooten DA, Campbell RL, Maislin G, McCauley KM, Schwartz JS. Transitional care of older adults hospitalized with heart failure: a randomized, controlled trial. J Am Geriatr Soc. 2004;52(5):675-684. https://doi. org/10.1111/j.1532-5415.2004.52202.x

2. Centers for Medicare \& Medicaid Services. Medicare and Medicaid programs; revisions to requirements for discharge planning for hospitals, critical access hospitals, and home health agencies, and hospital and critical access hospital changes to promote innovation, flexibility, and improvement in patient care. Fed Regist. 2019;84(189):51836-51884. https://www. govinfo. gov/content/pkg/FR-2019-09-30/pdf/2019-20732.pdf

3. Manges KA, Wallace AS, Groves PS, Schapira MM, Burke RE. Ready to go home? Assessment of shared mental models of the patient and discharging team regarding readiness for hospital discharge. J Hosp Med. 2020;16(6): 326-332. https://doi.org/10.12788/jhm.3464

4. Weiss $M E$, Yakusheva $\mathrm{O}$, Bobay $\mathrm{KL}$, et al. Effect of implementing discharge readiness assessment in adult medical-surgical units on 30-day return to hospital: the READI randomized clinical trial. JAMA Netw open. 2019;2(1):e187387. https://doi.org/10.1001/jamanetworkopen.2018.7387

5. Institute of Medicine Committee on Quality of Health Care in America. Crossing the Quality Chasm: A New Health System for the 21st Century. National Academies Press; 2001.

6. Yakusheva $\mathrm{O}$, Lindrooth $\mathrm{R}$, Weiss $\mathrm{M}$. Economic evaluation of the $80 \%$ baccalaureate nurse workforce recommendation: a patient-level analysis. Med Care. 2014;52(10):864-869. https://doi.org/10.1097/MLR.0000000000000189 